\title{
Graves' Disease and Down Syndrome: Case Report
}

\author{
Fábio Ferreira do Espírito Santo ${ }^{1}$, Denise Rosso Tenório Wanderley Rocha ${ }^{1}$, \\ Alberto Krayyem Arbex ${ }^{1,2}$ \\ ${ }^{1}$ Division of Endocrinology, IPEMED Medical School, Salvador, Brazil \\ ${ }^{2}$ Visiting Scientist of the Harvard T. H. Chan School of Public Health, Harvard University, Boston, USA \\ Email: dante_de_cerberus@hotmail.com
}

Received 20 November 2015; accepted 11 January 2016; published 14 January 2016

Copyright (C) 2016 by authors and Scientific Research Publishing Inc.

This work is licensed under the Creative Commons Attribution International License (CC BY). http://creativecommons.org/licenses/by/4.0/

(c) $\underset{\mathrm{EY}}{0}$ Open Access

\begin{abstract}
Down syndrome (DS) is the most common chromosomal abnormality in humans, and the most frequent cause of mental retardation. Patients affected by this syndrome show an increased prevalence of autoimmune diseases. The most common of those is Hypothyroidism. We present a case report describing the association of Down syndrome with Hyperthyroidism. An 18-year-old patient presented with a history of recurrent throat infections and intermittent diarrhea, having developed a total alopecia areata within one month from the first visit to the physician. After consultations with general practitioners, he was directed to an Endocrinology Ambulatory and diagnosed with a clear case of Graves' disease associated with Down syndrome. Treatment was started with methimazole $20 \mathrm{mg} / \mathrm{day}$, and after two months, was adjusted to $40 \mathrm{mg} /$ day. The patient reached adequate clinical and laboratory balance after five months of treatment. Thus, the association between Down syndrome and Graves' Disease is relevant in medical practice, due to its specific characteristics on diagnosis, and the need of an adequate treatment regarding this disease association.
\end{abstract}

Keywords

Down Syndrome, Graves' Disease, Alopecia Areata, Methimazole, Thyroid Gland

\section{Introduction}

The thyroid gland is the first endocrine gland that arises in the human embryo, developing as a diverticulum of the primitive pharynx in the third week of intrauterine life. In the human embryo, the primary thyroid follicles are recognized in the eighth week. The function of the follicular cells mainly depends on the protein synthesis of 
thyroglobulin and thyroid peroxidase. The synthesis of thyroglobulin begins between the ninth and tenth week, and the ability to perform iodine uptake and organification, as well as to incorporate it into thyroglobulin molecule begins around the tenth and eleventh week. The final function of the follicles (colloid accumulation in the interior) is observed around the thirteenth and fourteenth week [1].

As part of the hypothalamic-pituitary-thyroid axis, the thyrotropin-releasing hormone (TRH) is synthesized by the hypothalamus and acts on the anterior pituitary controlling the synthesis and release of thyrotropin (TSH). TSH binds to thyroid receptors and stimulates the synthesis and release of thyroid hormones (TH): triiodothyronine (T3) and tyroxine (T4). In turn, the TH binds to specific nuclear receptors inhibiting the secretion of TRH in hypothalamic level and TSH in hypophyseal level ("negative feedback") [2] [3].

There are several conditions that may cause thyroid hypofunction and hyperfunction, diagnosed by TSH and free T4 lab tests. Goiter means any increase in thyroid volume, and it can be diffuse or nodular.

\section{Hyperthyroidism, Thyrotoxicosis and Graves' Disease}

Hyperthyroidism refers to the excessive synthesis and high secretion of thyroid hormones. Thyrotoxicosis, in turn, is a clinical syndrome that results from high circulation levels of thyroid hormones, causing a generalized acceleration of metabolism. By far the most common cause of thyrotoxicosis is Graves' disease, followed by multinodular goiter and toxic adenoma [3].

Graves' disease is an autoimmune disease in which the thyroid gland is stimulated by autoantibodies against the TSH receptor (TRAB). It was described completely in 1835 by Robert Graves and comprises $80 \%$ of the cases of hyperthyroidism. Women are affected 5 to 10 times more than men. It is uncommon before 5 years of age, increases during puberty and has its peak incidence observed between 20 and 40 years of age. It is a less common disease in blacks, but equally prevalent in Caucasians and Asians [2] [4]-[8].

Despite a strong familial predisposition, to date, no specific gene has been linked to Graves' disease. Thus, there must be also environmental factors that exert great influence on the development of the pathology. Stress, smoking, infection (viral or bacterial) and excessive intake of iodine (particularly in geographical areas poor on this element) would be some of these risk factors [2] [4] [7].

Furthermore, Graves' disease may be associated with other autoimmune endocrine disorders (type 1 diabetes mellitus, Addison's disease, autoimmune oophoritis, ACTH isolated deficiency, etc.) and non-endocrine (myasthenia gravis, systemic lupus erythematosus, rheumatoid arthritis, Sjögren's disease, pernicious anemia, chronic active hepatitis, vitiligo, Down's syndrome, etc.) [7] [9]-[11].

Graves' disease presents with three classic clinical features: hyperthyroidism with diffuse goiter, infiltrative ophthalmopathy and dermopathy ("pretibial myxedema"). The most common manifestations of hyperthyroidism include nervousness, insomnia, fatigue, hot and dry skin, excessive sweating, tachycardia, palpitation, weight loss, polyphagia, diarrhea, tremors and heat intolerance. Regarding goiter, Graves' disease it is typically diffuse (97\%). It can be asymmetrical or lobular with variable volume. But there is a finding considered exclusive of the disease: the presence of "thrilling" murmur of the gland, produced by the notable increase in local blood flow. Any patient presenting with a diffuse goiter and hyperthyroidism should raise the hypothesis of Graves' disease as a diagnosis until otherwise proven [2] [6] [7]. The ophtalmopathy is present in $50 \%$ of patients with Graves' disease. It is due to the increased volume of extra ocular muscles and retro bulbar fat, generating an increase in intraorbital pressure. Consequently, protrusion of the eyeball may occur (called "exophthalmia" or "proptosis") along with decreased venous drainage resulting in per orbital edema, conjunctiva hyperemia and chemosis. Both orbits are affected, but in the beginning the manifestations may be clinically unilateral (20\%). The most common ocular manifestation in Graves' disease is eyelid retraction, fixed or scared look and "lid-lag" signal (delayed descent of the upper eyelid when the eyeball is moved down). The periorbital edema and exophthalmiastrongly suggest the diagnosis of Graves' disease [2] [7] [12].

Thyroid dermopathy or pretibial myxedema is exclusively found in Graves' disease. Considered a rare condition, it consists of a thickening of the skin, particularly over the lower region of the tibia, due to the accumulation of glycosaminoglycans. It affects only $5 \%$ to $10 \%$ of patients, being more common among women than in men (3.5:1) and is almost always associated with infiltrative ophthalmopathy (often severe) and high levels of TRAB. The lesions present as plaques, with very thickened skin, an aspect of orange peel and violet color. In less than $1 \%$ of the cases, it may be seen in other locations, such as hands and shoulders [6] [7].

Another common manifestation of Graves' disease is onycholysis ("Plummer's nail") which is best described 
as its separation from the nail layer due to faster nail growth [2] [7].

\subsection{Laboratory Diagnosis}

Classical laboratory findings in hyperthyroidism include TSH suppression, T3 and free T4 increase.

Occasionally, in about 5\% of cases, only the T3 is high, following the suppression of TSH ("T3-toxicosis"). This situation is shown more common in the early stage of the disease or in cases of relapse. Furthermore, it is possible to find initially only low levels of TSH, with normal T4 and T3 levels (subclinical hyperthyroidism). On the other hand, in seriously ill patients a TSH suppression can be found, together with low levels of free T4 (FT4) and T3, characterizing the "Sick Euthyroid Syndrome"[2] [7].

Antithyroid antibodies such as antithyroglobulin (anti-Tg) and anti-thyroperoxidase (anti-TPO) are observed in many patients with Graves' disease, but at lower titles than those found in Hashimoto's thyroiditis. However, the presence of TRAB has a great specificity for Graves' disease, indicating disease activity [2] [7].

\subsection{Treatment}

As an autoimmune disease, Grave' disease has a tendency to develop relapses and remissions. There is no cure and optimal treatment, correcting the autoimmune responses, is not available. The management consists of interventions that reduce the thyroid's ability to respond to abnormal stimulation by TRAB. The three basic treatment options are antithyroid medications (thioamides), surgery and radioactive iodine [2] [4] [6] [7].

There are three antithyroid drugs: methimazole (MMI), carbimazole (used mainly in the UK and parts of the British Commonwealth) and propylthiouracil (PTU). In general, therapy with antithyroid drugs as a first treatment option is most useful in young patients with small glands and mild disease. The therapy is usually initiated with higher doses and, when the patient becomes biochemically euthyroid, one can make maintenance therapy at a lower dose. The drug is usually administered for $1-2$ years and then it is assessed if the dose is adjusted or discontinued in order to evaluate whether the patient had remission (normal thyroid function one year after drug discontinuation) [2] [7] [13].

As for the side effects of thioamides, the frequency is added to the first 6 months of treatment. The most common reactions are allergic in nature (itching and rash) and epigastralgia, from $5 \%$ to $10 \%$ of patients. Among the serious side effects have agranulocytosis (absolute granulocyte count $<500 / \mathrm{mm}^{3}$, occurring at $0.2 \%$ to $0.5 \%$ of patients and can be life threatening if the drug is not discontinued) and hepatotoxicity (PTU can cause fulminant hepatic necrosis, and potentially fatal, while the MMI can cause potentially cholestatic liver toxicity) [2] [7].

Radioiodine has been used to treat hyperthyroidism since 1941. In the United States of America, is the preferred treatment for most patients over 21 years of age. It aims to control hyperthyroidism, the gland destroying and making the hypothyroid patient. It is administered orally (in solution or capsules) and has low cost. It can be used as initial therapy or as definitive therapy of second line, when there were relapses after antithyroid drugs. Most cost-effective therapy is considered the optimal dose of radioactive iodine is still controversial: most experts prefer the use of fixed dose (10,12 or $15 \mathrm{mCi}$ ), while others prefer the method in which the dose is calculated based on the size of the thyroid and its ability to capture iodine. The relative contraindications to this treatment include: Graves' eye disease, bulky goiters and refusal of the patient. However, pregnancy and lactation are absolute contraindications [2] [6] [7] [14].

Surgery (total thyroidectomy) is indicated in very bulky goiters (>150 g), in the existence of compressive symptoms in allergic patients or non-adherent to drug therapy, in patients who refuse treatment with radioactive iodine or in pregnant women with severe Graves' disease who are allergic or develop reactions to antithyroid drugs. Preoperatively, the patient should be prepared with a thyonamide (preferably 4 - 6 weeks are needed). In the 10 days before the procedure, should also be given potassium iodide in the form of saturated or Lugol solution 3 times/day mixed in water or juice. This scheme reduces the vasculature of the gland, reducing blood loss during surgery [2] [6] [7] [15].

\section{Down Syndrome}

Chromosomes may occasionally undergo some changes during mitosis and meiosis processes, resulting in chromosomal abnormalities. The clinically significant abnormality type is aneuploidy (abnormal number of chromosomes due to an extra chromosome or autosomal trisomy (three instead of the normal pair of one chro- 
mosome) is the most frequent aneuploidy. The most common type of viable human aneuploidy is Down syndrome or trisomy at chromosome band 21q22, corresponding to 95\% of cases. John Langdon Down, the British physician, was the first to describe the syndrome characteristics that bears his name. He presented detailed description of Down syndrome in 1866 [16] [17].

Although its etiology is not yet clearly established, there are endogenous and exogenous risk factors related to it. One of the main risk factors is advanced maternal age. As for external factors, exposure to ionizing radiation, consumption of alcohol, tobacco and illicit drugs are cited as causal factors of aneuploidy. [14] [18]

\subsection{Disease Profile: Down Syndrome}

Individuals with Down syndrome show a variable delay in mental development, and specific phenotypic characteristics, such as brachycephalia (very small frontal-occipital diameter, palpebral fissures with upper slope, epicanthal folds, flat nasal bridge and hypoplasia of the middle region of the face). Short neck is also common; a single palmar fold may be present; the tongue is protruding and hypotonic; there is clinodactyly of the fifth chirodactyl and increased distance between the big toe and the second toe. Frequently, children with Down syndrome also have generalized muscle hypotonic [18].

\subsection{Health Problems Related to Down Syndrome}

Children with Down syndrome are more likely to present a health impairment due to congenital abnormalities and predispositions characteristics of the syndrome. Among the major commitments are: [11] [15] [19]:

1) Cardiac disorders: Congenital heart defects are present in $50 \%$ of cases. The most common problems are atrioventricular canal defect, ventricular septal defect, atrial septal defect and tetralogy of Fallot.

2) Lung diseases: Most children with Down syndrome have frequent colds and recurrent pneumonia. This is due to an immune predisposition and the hypotonic muscles of the respiratory tract.

3) Atlantoaxial instability: This modification consists in an increase in the intervertebral space between the first and second vertebrae of the cervical spine, caused by anatomical abnormalities (hypoplasia of the odontoid process) and muscle-ligamentous hypotonic. It reaches $10 \%-20 \%$ of children and young people with Down syndrome and may lead to subluxation and spinal cord injury at the cervical level, causing neurological impairment (both sensitive and motor) or death (secondary to respiratory arrest due to injury of the medullary respiratory center).

4) Endocrinopathies: The most common hormonal dysfunction in individuals with Down syndrome is hypothyroidism, occurring in approximately $10 \%$ of children and $13 \%$ to $50 \%$ of adults. The presence of this pathology contributes to obesity in these patients, as well as harms the intellectual development of the child, if not correctly treated.

5) Visual problems: are very common in children with the syndrome. Myopia (50\%), hyperopia (20\%), astigmatism, strabismus, amblyopic, nystagmus and cataracts are the most common disorders.

6) Hearing problems: About $60 \%$ to $80 \%$ of children with the syndrome have uni- or bilateral hearing loss. Hearing deficits are mild or moderate in most cases and can be caused by the increase of cerumen in the ear canal, accumulation of secretions in the middle ear and frequent ear infections (due to the abnormal form of the ossicles in the middle ear). Hearing loss can also harm the overall development of the child.

7) Other associated problems: humor disorders, depression, Alzheimer's disease, autism and leukemia are associated with Down syndrome.

\section{Case Report}

G.J.M., 18 years old, male, melanoderm, born and raised in Feira de Santana, Northeastern region of Brazil, was admitted to an Endocrinology Ambulatory on 09 November 2014. According to his mother, he presented vomiting complaints, recurrent sore throat, fever and hair loss.

His mother also reported that 1 year before the patient began presenting repeated sore throat episodes, always accompanied by fever (not measured) and vomiting. The patient told he was always taken to the Basic Health Unit (BHU) in the neighborhood where he lives, with improvement in symptoms after the use of medications that he was not aware of. But in recent months the frequency of seizures increased and, in the last 30 days, progressive hair loss was observed. 
He denied headache, dizziness, earache, runny nose, cough, dyspnea, chest pain, palpitations, abdominal pain, diarrhea, constipation, dysuria, urinary burning and insomnia, but claimed observing "him more restless, distressed" and "thickening of the legs". He denied rash or skin lesions prior or concomitant to loss of nails, but complained about the occurrence of fragile and brittle nails.

As for past medical history, the mother said that the patient is carrier of Down syndrome. It was denied that he made use of continuous medication and or would have hypertension, dyslipidaemia or diabetes mellitus.

Born preterm natural childbirth (approximately 32 weeks), the mother claimed that the patient had low weight and required hospitalization before hospital discharge. He described having had repetitive situations of viral infections and verminosis during childhood, not specified.

The mother denies other cases of Down syndrome in the family. She denied systemic arterial hypertension, diabetes mellitus, dyslipidaemia, thyroid diseases or alopecia areata. She also pointed out that the patient never attended schools or institutions specializing in care for the disabled, citing a lack of resources. Denied the use of alcohol, tobacco or illicit drugs, it has positive epidemiology for schistosomiases and negative for Chagas disease.

On physical examination, the patient has good general and nutritional status, is lucid, eupneic, flushed and anicteric. Anthropometric data: Body mass $=57.0 \mathrm{~kg}$. Height $=165.0 \mathrm{~cm}$. Body mass index $=20.94 \mathrm{~kg} / \mathrm{m}^{2}$. Radial pulse $=96 \mathrm{bpm}$. Respiratory rate $=16 \mathrm{ipm}$. Blood pressure $=120 \times 80 \mathrm{mmHg}$.

HEAD: Symmetric, brachycephaly; no scalp and face injuries; absence of hair, eyebrows and eyelashes (Figure 1).

NECK: Symmetric; topic thyroid with normal volume, fibroelastic, mobile, painless, without palpable nodules, and no murmurs or thrills; absence of lymphadenopathy

CHEST: Symmetric; absence of skin lesions; lack of hair.

RESPIRATORY TRACT: Preserved expandability; normal thoracolumbar vocal tremor; vesicular murmur and distributed without adventitious sounds.

CARDIOVASCULAR TRACT: Quiet precordium; stroke invisible, but palpable in 5th left intercostal space in the mid-clavicular line; rhythmic sounds phonetically normal in two times, no murmurs.

ABDOMEN: Symmetric; plain; absence of hair; flaccid; painless on palpation; without masses or visceromegaly; no murmurs; normal hydro-aerial noises.

GENITALIA: Absence of pubic hair; absence of ulcers or secretions; topics testicles, painless, mobile and trophic; absence of mass in inguinal regions. Tanner: G5.

EXTREMITIES: Symmetric upper limb without skin lesions, hairless, well perfused and without edema; Symmetrical legs with discrete cutaneous thickening plates in lower third of the legs, hairless, well perfused and without edema; absence of onycholysis.

NEUROLOGICAL EXAMINATION: normal walk; tremors in hands; normal patellar reflexes.

The mother reported that the patient underwent a preliminary assessment with an otolaryngologist that would

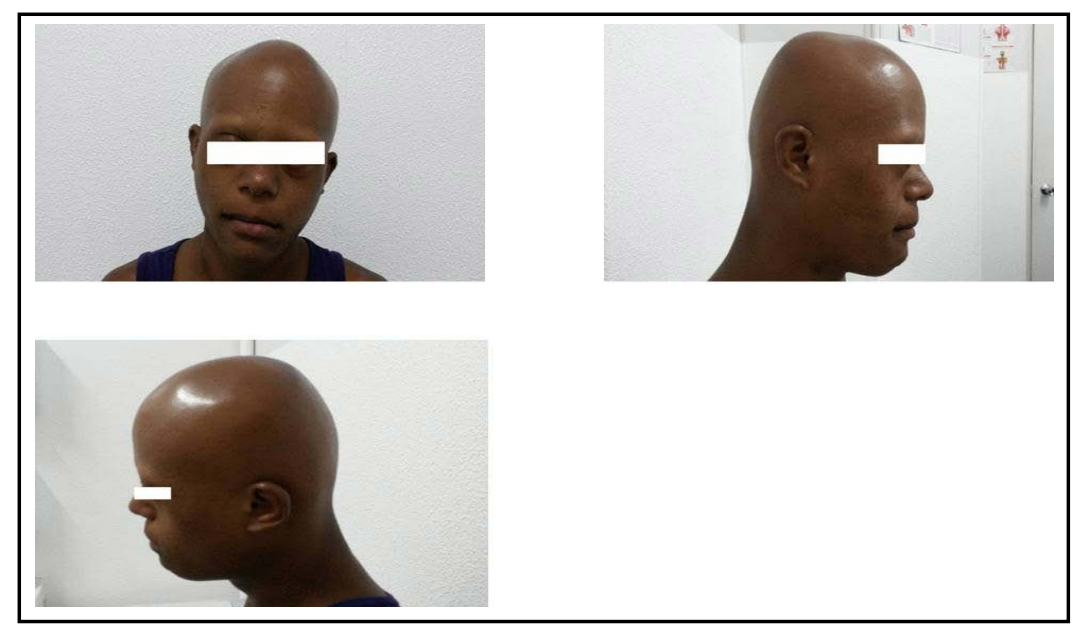

Figure 1. Characteristics of patient G.J.M. in 09/05/2014. Symmetrical and brachycephalia head; no scalp and face injuries; complete absence of hair, eyebrows and eyelashes. 
have diagnosed rhinitis and requested a thyroid ultrasound. The results of this exam were, on 15/08/2014: "a topic thyroid, with regular borders and heterogeneous echogenicity. Multiple hypoechoic and echogenic areas, diffusely throughout its parenchyma; right lobe measuring $4.3 \times 1.7 \times 2.0 \mathrm{~cm}$ with volume of $8.1 \mathrm{~cm}^{3}$; left lobe measuring $4.5 \times 1.6 \times 1.9 \mathrm{~cm}$ with volume of $7.5 \mathrm{~cm}^{3}$; isthmus without alterations, with a volume of $0.9 \mathrm{~cm}^{3}$; total volume of the gland $16.5 \mathrm{~cm} 3$ [NR -4.8 to $\left.12.0 \mathrm{~cm}^{3}\right]$ ).

Based on the clinical history, the physical examination and complimentary exams, the diagnosis of DIFFUSE GOITER was defined, with its probable etiology related to Hyperthyroidism: GRAVES’ DISEASE. To confirm this diagnosis and allow a proper beginning of drug therapy, complementary exams were requested. On 09/09/2014 a TSH $<0.008 \mathrm{mU} / \mathrm{L}$ (suppressed TSH) was found. FT4 $=6.79 \mathrm{ng} / \mathrm{dl}$ (increased). FT3 $>20 \mathrm{ng} / \mathrm{dl}$, TRAB $>40.0$ $\mathrm{U} / \mathrm{L}$, Anti-TPO $>600 \mathrm{U} / \mathrm{ml}$.

In face of these lab results, the diagnosis of SECONDARY DIFFUSE GOITER DUE TO GRAVES' DISEASE was confirmed. Methimazole $10 \mathrm{mg}$ was prescribed (dose: 2 tablets in the morning), and thorough instructions were made regarding the disease's characteristics and its treatment, as well as the possibility of any serious side effects of the medication (with instructions on the procedures to be adopted in case of side effects). Follow-up tests after 45 days of the start of drug treatment were required.

On 27/11/2014 the patient returned to the ambulatory. The patient's mother reported that he was in continuous use of methimazole, as prescribed. The patient kept, however, postprandial vomiting and diarrhea episodes, although with a decreased frequency. She reported that the patient was taken to the gastroenterologist who prescribed "verminosis treatment". On that consultation, he also presented new exams: $(27 / 11 / 2014)$ TSH $<0.008$ $\mathrm{mU} / \mathrm{L}, \mathrm{FT} 4>30.0 \mu \mathrm{g} / \mathrm{dl}, \mathrm{T} 3=544.0 \mathrm{ng} / \mathrm{dl}$.

The doctors decided to double the dosage of the medication: $40 \mathrm{mg}$ of methimazole in a single dosage in the morning. Control tests were recommended to be carried out after 45 days.

On 03/02/2015, the patient and the mother returned. According to their report, the patient showed a significant improvement in symptoms of the gastrointestinal tract and did not present fever or sore throat during that period. They were glad because of a discrete hair growth in the scalp and of the eyelashes during this period. The results of required control tests on 05/01/2015 were: FT4 $=1.55 \mathrm{ng} / \mathrm{dl}$, FT3 $=5.8 \mathrm{ng} / \mathrm{dl}$, TRAB $\geq 40.0 \mathrm{U} / \mathrm{L}$. Based on the important clinical recovery and on these results, an option to keep the drug therapy was made, with recommendation for further tests after 60 days.

However, the patient returned after five months in continuous use of prescribed medication, with reversal of alopecia areata (Figure 2) and bringing new control tests: on 06/05/2015, FT4 = $1.5 \mathrm{ng} / \mathrm{dl}$, TRAB $=>40.0 \mathrm{U} / \mathrm{L}$. The conduct adopted was to maintain methimazole dose.

\section{Conclusions}

Patients affected by Down syndrome, a condition associated with impairment of the immune system, are more likely to develop recurrent infections and autoimmune diseases. Amongst the autoimmune diseases that affect these patients, type 1 diabetes mellitus, autoimmune thyroiditis, alopecia, celiac disease and the early development of Alzheimer's disease are the most important medical diagnoses to be looked for.

When it comes to thyroid disorders, autoimmune thyroiditis is the most common condition in patients with Down syndrome. The most common form in children and adolescents is Hashimoto's thyroiditis. Hyperthyroidism manifests itself less frequently in patients with Down syndrome. When it does, it usually presents as Graves' disease, showing the same characteristics of this pathology in the general population, except for presenting at earlier ages (children and adolescents), showing no female predominance, low incidence of ophthalmopathy and reduced clinical remission with methimazole.

In this presented case, it is important to point out the fact that the symptoms of hyperthyroidism occurred gradually, prevailing the altered bowel habits. Because the patient had repeated throat infections and intermittent diarrhea history, this symptom inadvertently went unnoticed at first, having caused a delayed diagnosis.

Alopecia areata was also a very significant sign in this case, presenting the universal form and quick installation due to the combination of genetic factors (change in chromosome 21) and immunologic (circulating autoantibodies).

It is necessary to lead a regular treatment towards normalization of signs and symptoms as well as thyroid hormone levels. Hyperthyroidism therapy in patients with Down syndrome basically does not differ from that employed in individuals without this clinical condition. Current medical literature suggested to treat Hypothyroi- 


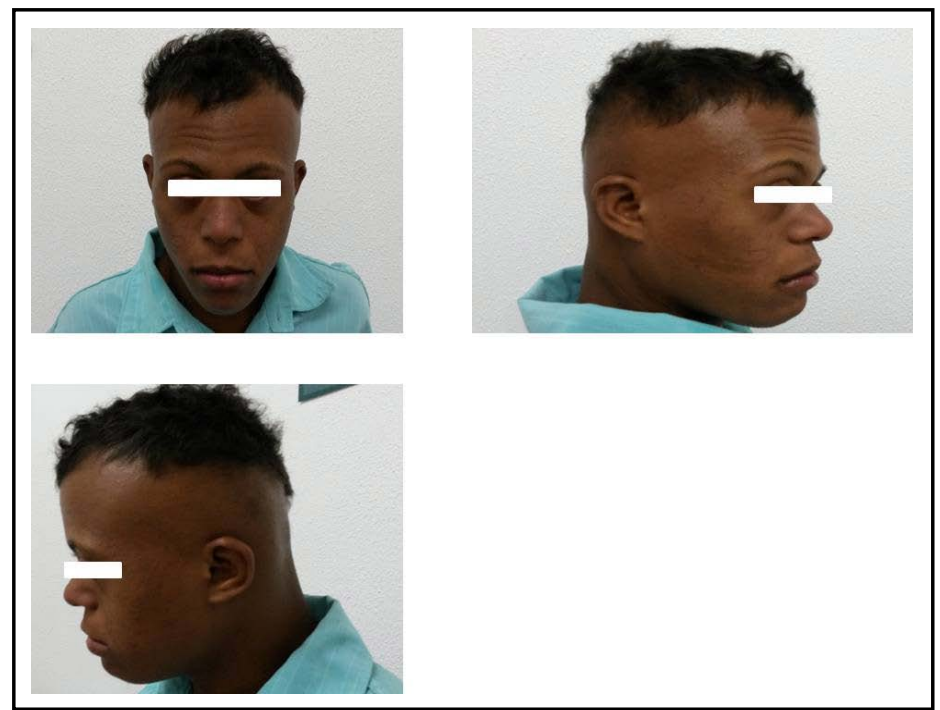

Figure 2. Patient G.J.M., characteristics on 04/09/2015, 5 months after continuous use of methimazole.

dism clinically up to 2 years after diagnosis, using thioamides (if serious side effects do not arise), and then planed the necessary definitive therapy, which would be radioiodine or surgery.

\section{Acknowledgements}

The authors would like to thank IPEMED Brazil for supporting continuing medical education.

\section{References}

[1] Kimura, E.T. and Zago, D.A. (2001) Embriologia e Histologia. In: Rosa, J.C. and Romão, L.A., Eds., Glândula Tireoide: Funções e Disfunções, Diagnóstico e Tratamento, 2nd Edition, Lemos Editorial, São Paulo, 19-25.

[2] Cooper, D.S. and Ladenson, P.W. (2013) Glândula Tireoide. In: Gardner, D.G. and Shoback, D., Eds., Endocrinologia básica e clínica de Greenspan. 9th Edition, AMGH, Porto Alegre, 163-226.

[3] Gadelha, P.S., Azevedo, M.F. and Montenegro, R.M. (2013) Interpretação dos Testes de Função Tireoidiana. In: Vilar, L., Ed., Endocrinologia Clínica, 5th Edition, Guanabara Koogan, Rio de Janeiro, 249-259.

[4] Weetman, A.P. (2000) Graves’ Disease. The New England Journal of Medicine, 343, 1236-1248. http://dx.doi.org/10.1056/NEJM200010263431707

[5] Sandrini, R., França, S.N., de Lacerda, L., et al. (2001) Tratamento do Hipertireoidismo na Infância e Adolescência. Arquivos Brasileiros de Endocrinologia \& Metabologia, 45, 32-36. http://dx.doi.org/10.1590/S0004-27302001000100006

[6] Neves, C., et al. (2008) Doença de Graves. Arquivos de Medicina, 22, 137-146.

[7] Freitas, M.C., Mota, V.C. and Vilar, L. (2013) Diagnóstico e Tratamento da Doença de Graves. In: Vilar, L., Ed., Endocrinologia Clínica, 5th Edition, Guanabara Koogan, Rio de Janeiro, 310-327.

[8] Wasniewska, M., et al. (2014) Epidemiological, Pathophysiological and Clinical Peculiarities of Graves’ Disease in Children with Down and Turner Syndrome: A Literature Review. Health, 6, 1447-1452. http://dx.doi.org/10.4236/health.2014.612178

[9] Karlsson, B., et al. (1998) Thyroid Dysfunction in Down’s Syndrome: Relation to Age and Thyroid Autoimmunity. Archives of Disease in Childhood, 79, 242-245.

[10] Goday-Arno, A., Cerda-Esteva, M., Flores-Le-Roux, J.A., et al. (2009) Hyperthyroidism in a Population with Down Syndrome (DS). Clinical Endocrinology, 71, 110-114. http://dx.doi.org/10.1111/j.1365-2265.2008.03419.x

[11] Iughetti, L., et al. (2015) Thyroid Function in Down syndrome. Expert Review of Endocrinology \& Metabolism, 10, 1-8. http://dx.doi.org/10.1586/17446651.2015.960846

[12] Bloise, W. (2001) Oftalmopatia da Moléstia de Graves. In: Rosa, J.C. and Romão, L.A., Eds., Glândula Tireoide: Funções e Disfunções, Diagnóstico e Tratamento, 2nd Edition, Lemos Editorial, São Paulo, 249-254. 
[13] Young, E.T., et al. (1988) Prediction of Remission after Antithyroid Drug Treatment in Graves’ Disease. Quarterly Journal of Medicine, 66, 175-189.

[14] Cruz Júnior, A.F., Takahashi, M.H. and Albino, C.C. (2006) Tratamento Clínico com Drogas Antitireoidianas ou Dose Terapêutica de Iodo-131 no Controle do Hipertireoidismo na Doença de Graves: Avaliação dos Custos e Benefícios. Arquivos Brasileiros de Endocrinologia e Metabologia, 50, 1096-1101. http://dx.doi.org/10.1590/S0004-27302006000600017

[15] Andrade, V.A., Gross, J.L. and Maia, A.L. (2001) Tratamento do Hipertireoidismo da Doença de Graves. Arquivos Brasileiros de Endocrinologia e Metabologia, 45, 609-618. http://dx.doi.org/10.1590/S0004-27302001000600014

[16] Nakadonari, E.K. and Soares, A.A. (2006) Síndrome de Down: Considerações Gerais sobre a Influência da Idade Materna Avançada. Arquivos doMudi, 10, 5-9.

[17] Matos, S.B., et al. (2007) Síndrome de Down: Avanços e perspectivas. Revista Saúde.com, 3, 77-86.

[18] Silva, N.L.P. and Dessen, M.A. (2001) Deficiência Mental e Família: Implicações para o Desenvolvimento da Criança. Psicologia: Teoria e Pesquisa, 17, 133-141. http://dx.doi.org/10.1590/s0102-37722001000200005

[19] Moreira, L.M.A., El-Hani, C.N. and Gusmão, F.A.F. (2000) A Síndrome de Down e sua Patogênese: Considerações sobre o Determinismo Genético. Revista Brasileira de Psiquiatria, 22, 96-99. http://dx.doi.org/10.1590/s1516-44462000000200011 